\title{
Formulation and Validation of Multidisciplinary Design Problem on Wear and Fatigue Life of Lead Screw Actuators
}

\author{
Krishna Meruva, Zhuming Bi, Donald Mueller, and Bongsu Kang \\ Department of Engineering, Indiana University-Purdue University Fort Wayne, Fort Wayne, IN 46805, USA \\ Correspondence should be addressed to Zhuming Bi; biz@ipfw.edu
}

Received 16 February 2013; Accepted 27 March 2013

Academic Editor: Dan Zhang

Copyright ( 2013 Krishna Meruva et al. This is an open access article distributed under the Creative Commons Attribution License, which permits unrestricted use, distribution, and reproduction in any medium, provided the original work is properly cited.

\begin{abstract}
Multidisciplinary design optimization has been widely applied in the optimization of large-scale complex system and also in the design and optimization of components, which are involved in multidisciplinary behaviors. The wear and fatigue life of lead screw actuators is a typical multidisciplinary problem. The wear behaviors of actuators closely relate to many factors such as loads, lubrications, materials properties, surface properties, pressures, and temperature. Therefore, the wear and fatigue life of actuators cannot be modeled without a simultaneous consideration of solid mechanics, fluid dynamics, contact mechanics, and thermal dynamics. In this paper, the wear and fatigue life of a lead screw actuator is modeled and validated. Firstly, the theory of asperity contact and Archard's model of sliding wear are applied to estimate the amount of wear under certain circumstances. Secondly, a test platform is developed based on a standard ASTM test protocol, and the wear phenomenon at the ball-on-flat sliding is measured to validate the developed wear model. Thirdly, finite element analysis is conducted using Nastran to assess the contact stresses in the lead screw and nut assembly model. The estimated data from the three sources are finally merged to formulate a mathematical model in predicting the wear and fatigue life for the optimization of lead screw actuators.
\end{abstract}

\section{Introduction}

Robotic technologies are playing more and more significant roles in our modern society. Robots are migrating from traditional manufacturing areas to our daily lives to assist or replace humans in completing tedious and routine tasks. Robots have gradually been applied in space, entertainment, military, agriculture, healthcare, and home environments. In answering the question about what emerging technology will cause another big stir in the way that the home computer did years ago, Bill Gates responded that robots will change the way people understand computers, and robots will interact with people in totally new ways [1]. However, many issues related in the field of robotics have not been addressed satisfactorily in terms of cost, precision, stiffness, reliability, energy efficiency, flexibility, robustness, and control. The ultimate goal of the presented work is to provide durable actuators for robotic design optimization from the perspective of cost and functionalities.
Robots are typical mechatronic products which need design knowledge from multiple disciplines such as mechanical engineering, electronic engineering, sensing technologies, artificial intelligence, and machine control [2]. Multidisciplinary design methodologies provide vital tools to support robotic design and applications. Since ro-botic systems are usually complex systems, decomposition and modularization is an effective way to manage system complexity [3-5]. Under a modularized architecture, robots can be treated as a set of basic modules, comprising rotary or linear modules as actuators and connecting modules for robotic structures. In particular, linear or rotary modules are essential to the majority of robots which need the capabilities of locomotion or manipulability. For examples, key components of a cuttingedge Exechon hybrid robot are three high-precision linear actuators [6,7], while a medical robot with three lowcost linear actuators provides a 3 DOF motion for ankle rehabilitation [8]. 


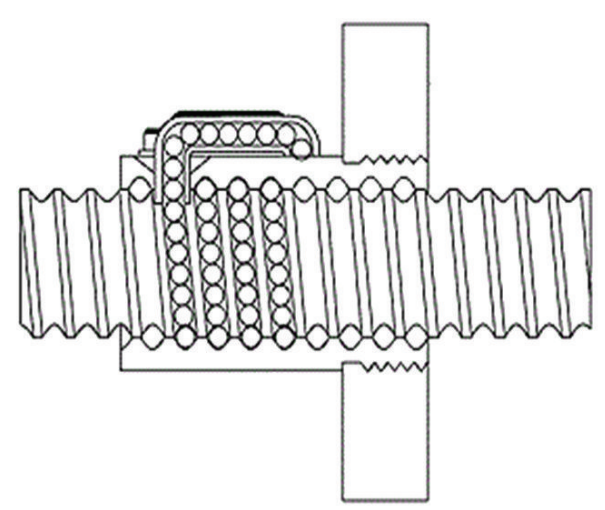

(a) Ball screw (Roton, inc.)

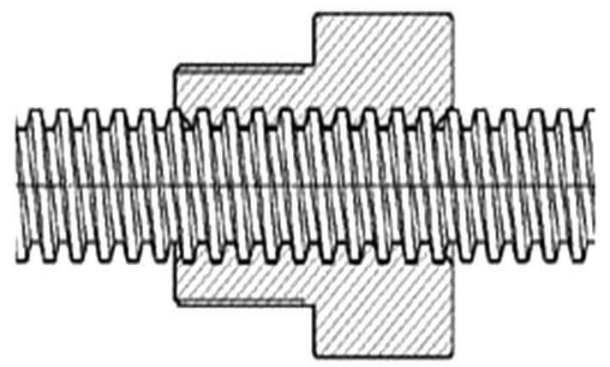

(b) Lead (acme/trapezoidal) screw

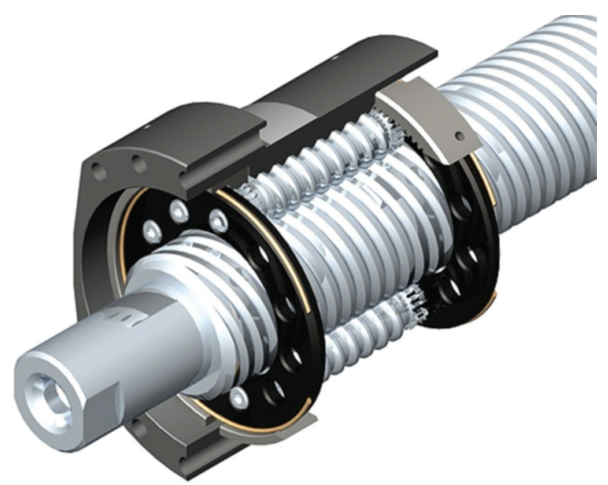

(c) Roller screw (Thomson linear inc.)

FIGURE 1: Types of power screw mechanisms used on linear actuators.

In designing a robot, linear actuators are selected based on many aspects such as cost, precision, maximized loads, maximized speeds, and stiffness [9]. Most of the design criteria are in conflict with each other. However, it is our observation that the methodologies and data are lacking to help robotic designers select modular components in particular, when the design criteria of precision, cost, and fatigue life have to be considered simultaneously to optimize the system performance of a robot. The focus of this paper is design of the low-cost lead screw linear actuators. Multidisciplinary design problem will be formulated to explore the intricate relationships of loads, wear, and fatigue life. The rest of paper is organized as follows. In Section 2, the design of lead screw actuators will be overviewed. In Section 3, the adhesive friction models are developed to correspond the loads and stresses with the wear. In Section 4, the experiment is set up to acquire test data and to verify the developed models. In Section 5, the presented work is summarized.

\section{Overview of Lead Screw Actuators}

A lead screw linear actuator is a mechanism that converts an input in the form of a rotary motion into a desired linear motion. The major benefits of using a lead screw mechanism in linear actuators are inherent mechanical advantage, high stiffness, high strength, and a cost-effective package. Lead screws fall under the category of power screws and can be classified into the following different types: ball screw, acme/trapezoidal screw and roller screw.

A ball screw, mechanism, as shown in Figure 1(a), consists of a ball screw and a ball nut with recirculating balls providing rolling contact between the nut and the screw. A large number of balls used in these assemblies facilitate the distribution of forces transmitted, resulting in a relatively small load per ball. These screws offer high efficiencies of around $90 \%$ due to the inherently low friction of the rolling elements.

An acme or trapezoidal screw, which hereafter will be addressed as lead screw, consists of a screw and a nut that are in sliding contact with each other. The screw is generally made up of alloy steel with a trapezoidal thread form, and the nut is typically made of an engineering polymer or bronze. The contact between the nut and the screw is a sliding contact; therefore friction plays a very important role in the performance and efficiency of the mechanism. These screws offer low efficiencies due to the relatively greater coefficient of friction in sliding.

As shown in Figure 1(c), planetary roller screws consist of a screw and a nut with planetary rollers. The barreled surfaces of all the rollers are used to transfer load from the nut to the screw [10]. Due to this increased load-bearing area, the roller screws can withstand higher dynamic loads with far greater life expectancy than either ball screw or lead screw mechanisms. In spite of the benefits that the ball and roller screws offer, they both tend to be far more expensive than 


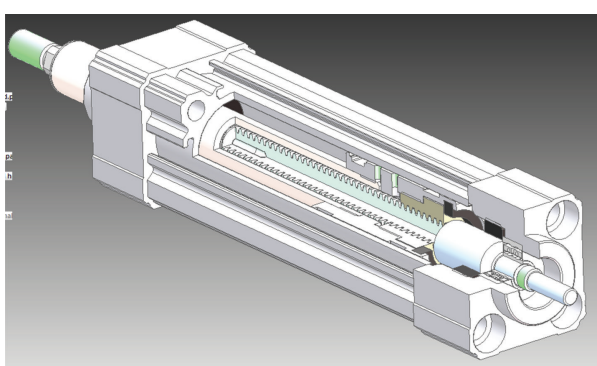

(a) Lead screw actuator

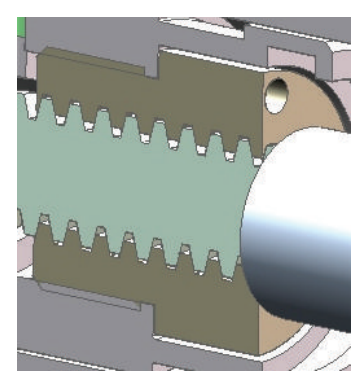

(b) detailed view of screw and nut

FIGURE 2: Lead screw cylinder (courtesy, PHD, Inc.).

lead screws. This is the reason why in applications where the operating speeds are lower and where life expectancy is not very high, lead screws offer a cost-effective design solution.

A typical single-axis linear actuator driven by a lead screw, as shown in Figure 2, consists of the following components: $a$ lead screw, lead nut, piston rod, cylinder tube, head, cap, radial ball bearing, electric motor, motor coupler, a mounting plate, and other miscellaneous hardware such as fasteners.

2.1. Lead Screw Thread Geometry. Lead screws have either an Acme or Trapezoidal thread profile. The acme threads, which are used on inch size screws, have a $14.5^{\circ}$ flank angle with a total included angle of $29^{\circ}$ as shown in Figure 3. The trapezoidal screws, on the other hand, are used on metric size screws, having a $15^{\circ}$ flank angle and an included angle of $30^{\circ}$.

Pitch and lead are closely related as shown in Figure 4. Pitch is the distance between the crests or troughs of two consecutive threads. Lead is the distance traversed along the axis of the screw, by one complete rotation, or $360^{\circ}$, of the screw:

$$
\begin{aligned}
& \text { single-start thread, } P_{h}=P \\
& \text { double-start, } P_{h}=2 P \\
& \text { three-start, } P_{h}=3 P .
\end{aligned}
$$

2.2. Screw Mechanics. The primary function of a lead screw is to traverse a load $F$ axially, through a specified linear distance, $L$, called travel. It is a single-degree-of-freedom mechanism with the travel constrained between a full extent and full retract position. The nut, which is engaged with the screw, is generally the linearly traveling member, whereas the screw is the rotating member driven by a prime mover like an electric motor or by hand. Assuming that the screw is driven by an electric motor at an angular velocity of $n$, linear velocity $v$ of the nut is given by

$$
v=n \cdot P_{h}
$$

where $v: \mathrm{m} / \mathrm{s}, n$ : revolutions/minute, and $P_{h}: \mathrm{m}$.

A single-start threaded screw with pitch $P$ and helix angle $\lambda$ is shown in Figure 5. Consider that a single thread of the screw is unrolled for exactly one turn. The force diagram for lifting the load is shown in Figure 6(a), where the lifting force

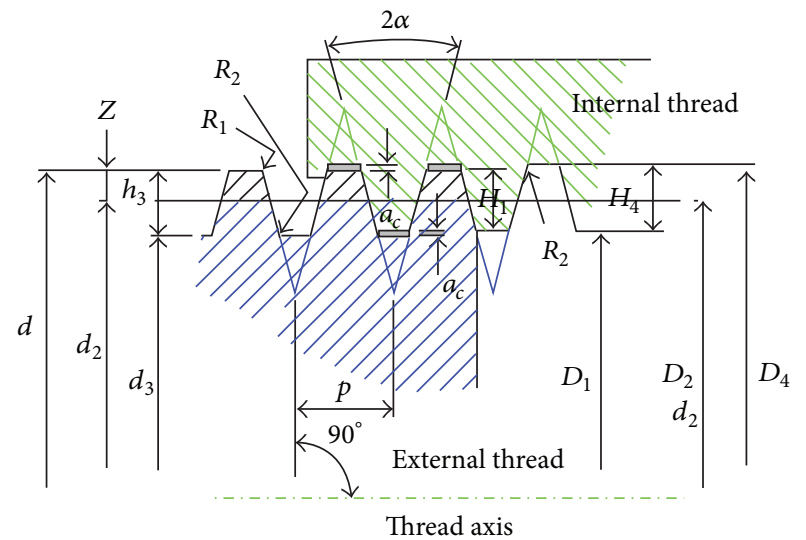

FIgURE 3: Trapezoidal thread profile, Din 103-4 (http://www.roymech.co.uk/). Legends: $D_{s}:$ Nominal or major diameter of screw, $D_{n}$ : nominal or major diameter of nut, $K_{s}$ : minor diameter of screw, $K_{n}$ : minor diameter of nut, $E$ : pitch diameter, $P:$ pitch, $P_{h}$ : Lead, $\alpha$ : flank angle $\left({ }^{\circ}\right), h_{s}$ : depth of thread of screw, $h_{n}$ : depth of thread of nut, $h_{e}$ : depth of thread engagement.

$F_{r}$ is positive. Similarly the force diagram for lowering the load is shown in Figure 6(b), where the lowering force $F_{l}$ is negative [11]. The torque required to raise, $T_{r}$, or to lower, $T_{l}$, the load while overcoming the friction is given by

$$
\begin{aligned}
& T_{r}=\frac{F E}{2}\left(\frac{\pi \mu E+P_{h} \cos \alpha_{n}}{\pi E \cos \alpha_{n}-\mu P_{h}}\right), \\
& T_{l}=\frac{F E}{2}\left(\frac{\pi \mu E-P_{h} \cos \alpha_{n}}{\pi E \cos \alpha_{n}+\mu P_{h}}\right),
\end{aligned}
$$

where $\lambda=$ helix angle of the screw, $\mu=$ coefficient of friction (dry), $\alpha_{n}=$ flank angle measured in normal plane, $\alpha=15^{\circ}$ (metric trapezoidal thread), and $n_{s}=$ number of starts;

$$
\begin{gathered}
P_{h}=P n_{s}, \\
\tan \alpha_{n}=\tan \alpha \cos \lambda, \\
\tan \lambda=\frac{P_{h}}{\pi E} .
\end{gathered}
$$




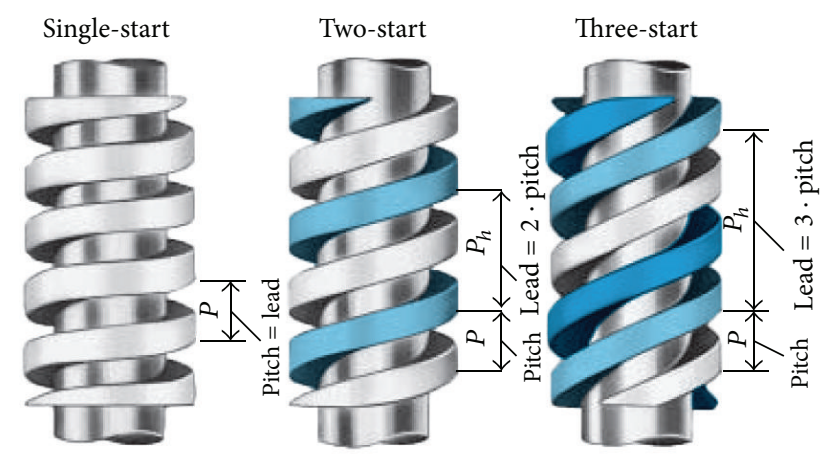

FIGURE 4: Singlestart and multistart threads (http://www.kammerer-gewinde.com/).

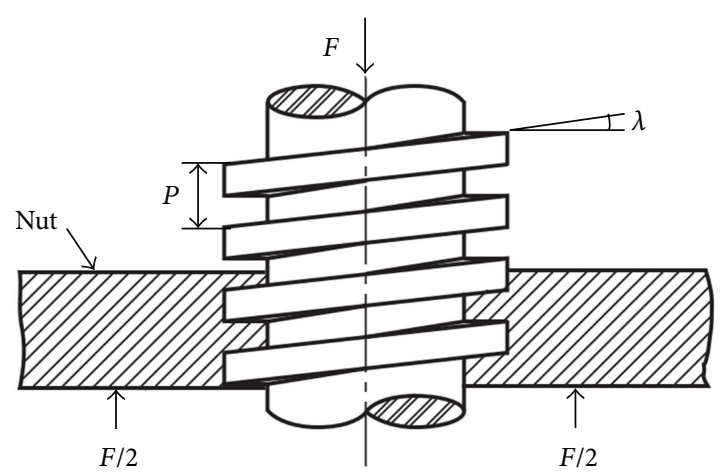

FIGURE 5: Free body diagram of lead screw [11].

One advantage of using a lead screw over other screws is its inherent ability to self-lock. This condition occurs when the torque required to lower the load $T_{l}$ in (3) is greater than zero:

$$
\pi \mu E>P_{h} \cos \alpha_{n} \quad \text { or } \quad \mu>\tan \lambda \cos \alpha_{n} .
$$

The physical interpretation of (5) is that self-locking of a lead screw mechanism occurs when the coefficient of friction between the surfaces of the screw and nut in sliding contact is greater than the product $\tan \lambda \cos \alpha_{n}$. The screw efficiency is given by [12]:

$$
\eta=\frac{\tan \lambda(1-\mu \sec \alpha \tan \lambda)}{(\mu \sec \alpha+\tan \lambda)} .
$$

From (6) it can be seen that the efficiency $\eta$ of a lead screw mechanism is dependent on coefficient of friction between the two surfaces in contact, the helix angle $\lambda$ and the flank angle. Out of these, the coefficient of friction is the most important factor influencing the performance of linear actuators using these mechanisms. Typical values of coefficient considered for different material combinations are given in (Table 1).

\section{Adhesive Wear Model}

Friction and the corresponding resultant wear between a metal and a nonmetal mating pair has been studied and
TABLE 1: Friction values for unlubricated common nut materials at room temperatures.

\begin{tabular}{lcc}
\hline Screw & Nut & Coefficient of friction \\
\hline \multirow{3}{*}{ AISI 1055 steel } & Cast iron GC & 0.18 \\
& Steel & 0.15 \\
& Bronze CuSn & 0.1 \\
& Plastic & 0.1 \\
\hline
\end{tabular}

researched a great deal by many in the past. However, due to the complexity of wear phenomenon, a unified, consistent, and accurate model does not exist for the material pair of metals and nonmetals. At the outset, it is important to understand the different types of wear, before attempting to formulate a model for a given case.

According to Burwell [13], there are four main forms of wear-adhesive, abrasive, corrosive, and surface fatigue wear. Adhesive wear is a type of wear between two soft surfaces in sliding contact with each other, where material is pulled off one surface and adheres to the other. An Abrasive wear occurs when a rough hard surface, or a soft surface with embedded hard particles on its surface, slides on a softer surface and causes a series of grooves on it. Corrosive wear is a process where wear occurs in a corrosive environment. Lastly Surface fatigue wear is observed during repeated sliding or rolling over a track. The repeated loading and unloading cycles to which the materials are exposed may induce the formation of surface or subsurface cracks, which eventually result in breakup of the surface with the formation of large pits on the surface [14].

Determining the type of wear responsible by examining a failed component is often a complex task [14]. Based on the studies conducted by Burwell [13]; Fuman et al. [15]; Love [16]; Ronan et al. [17], adhesive wear is believed to be the most common form of wear and also the least preventable. In all the mechanical systems where two solids are in sliding contact with each other, the adhesive wear is the primary form of wear. Although this form of wear is the most common, the wear rates are usually very low [14]. Only an unexpected occurrence of other forms of wear, for example, abrasive wear, often produces unexpectedly high wear rates and early failure of mechanism.

In particular adhesive wear occurs whenever one solid material is slid over the surface of another or is pressed against it. The wearing off of material takes the form of small particles or asperities, which are usually transferred to the other surface, but which may come off in loose form [14].

The process of adhesive wear can be explained with the help of Figure 7, wherein a softer part shown on top is sliding on a harder bottom part. Out of the two surfaces shown in the figure, the first surface is the physical interface between the two parts, and the second surface is a continuous surface inside the softer part on the top. When a tangential displacement is applied to one of the two parts parallel to the plane of the interface, shearing could happen along either of the two surfaces. If the force required to break through the interface of the materials is larger than the force required for breaking through some continuous surface 


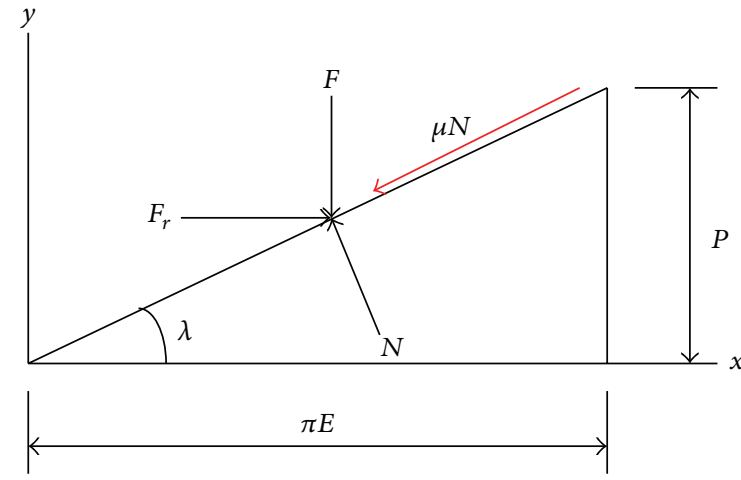

(a)

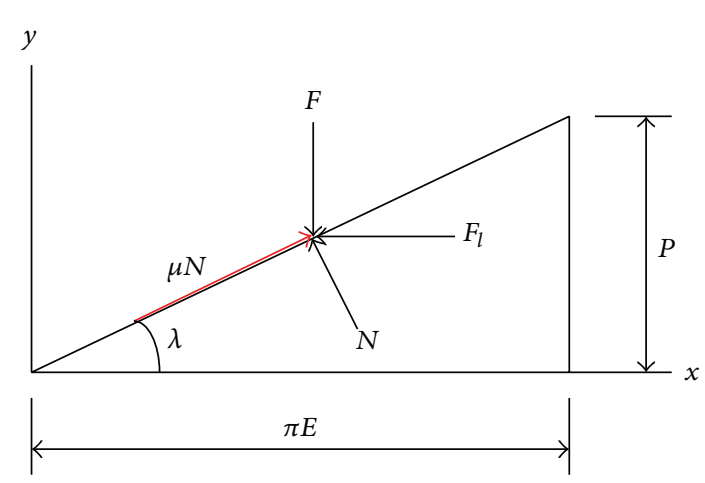

(b)

FIGURE 6: (a) Force diagram for lifting the load and (b) for lowering the load.

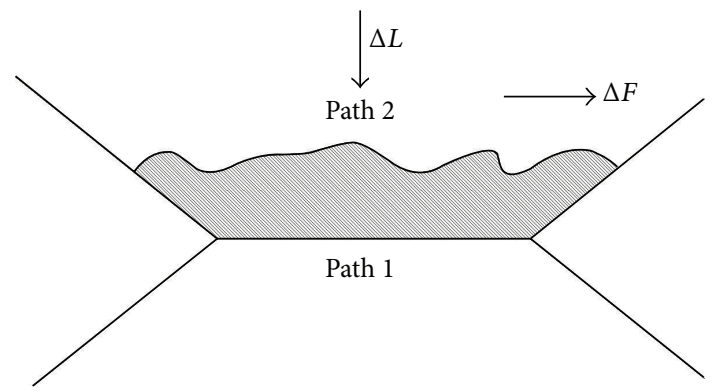

Figure 7: Adhesive junction being sheared.

inside one of the materials, the break will occur along this latter surface. However, wear tests performed on different material combinations by Archard and Hirst showed that shearing along a surface inside of one the materials is very unlikely. Hence the break during shearing is most likely to occur at the interface.

The adhesive wear model, based on Archard's wear law, which is commonly used in practice, is utilized to compute theoretical wear:

$$
W=K \cdot F \cdot V \cdot t,
$$

where $W$ = wear volume $\left(\right.$ in $\left.^{3}\right), K=$ wear factor $\left(\right.$ in $^{3}-\mathrm{min} / \mathrm{ft}-$ lb-hr), $F=$ nomal load (lb), $V=$ sliding velocity $(\mathrm{ft} / \mathrm{min}), t=$ elapsed time (hours).

Using this model, wear volume is calculated using a ballon-flat sliding model. A $0.5 \mathrm{in}$. diameter ball made of 1060 steel is used to apply different normal loads on a flat plate made of Torlon PAI 4301 polymer. The contact stresses that act at the ball and plate junction are calculated, as listed in Table 2, using Hertzian contact stress model, which has been illustrated in Figure 16. These values are furthermore verified by performing finite element analysis of the assembly as shown in Figures 8 and 9. Also shown below in Figures 10 and 11 are the graphs representing the wear volume caused by sliding of the steel ball on plate.

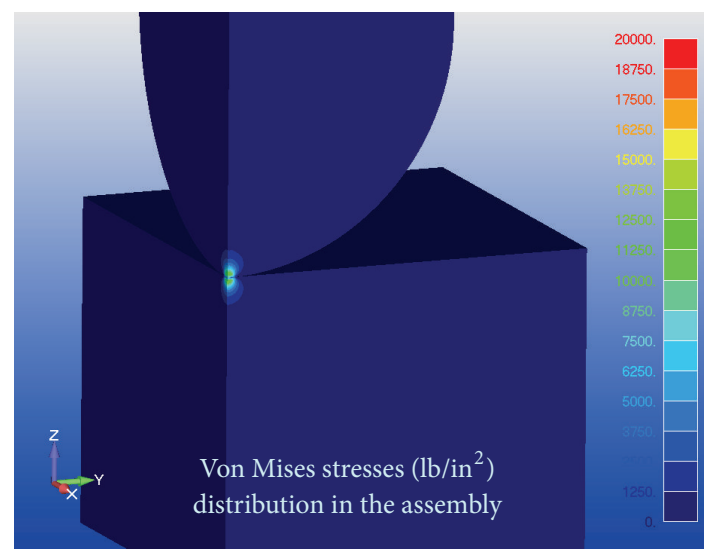

FIGURE 8: Ball-on-plate quarter FEA model.

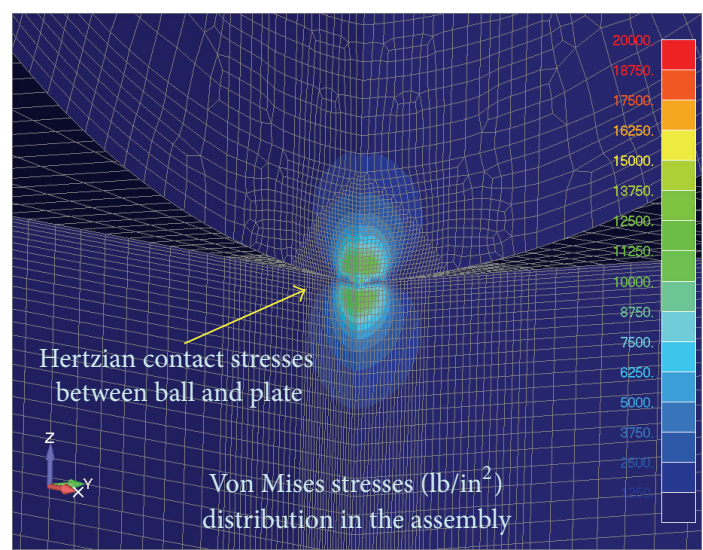

Figure 9: Contact stresses at the interface between ball and plate.

\section{Measurement and Validation of Wear}

4.1. Sliding Wear Test. For determining the sliding wear of the polymer material used as the lead screw nut, a standard test setup using a linear, reciprocating ball-on-flat plane geometry is utilized [18]. The direction of the relative motion between 
TABLE 2: Operating parameters used to compute wear volume.

\begin{tabular}{lccccc}
\hline Sample no. & Load $F(\mathrm{lb})$ & $\begin{array}{c}\text { Velocity } V \\
(\mathrm{ft} / \mathrm{min})\end{array}$ & $\begin{array}{c}\text { Contact stress } P \\
\left(\mathrm{lb} / \mathrm{in}^{2}\right)\end{array}$ & $P V$ value $\left(\mathrm{lb} \cdot \mathrm{ft} / \mathrm{in}^{2} \cdot \mathrm{min}^{2}\right)$ & $\begin{array}{c}\text { Wear factor } K \\
\left(\mathrm{in} \cdot \mathrm{min}^{3} \mathrm{ft} \cdot \mathrm{lb} \cdot \mathrm{hr}\right)\end{array}$ \\
\hline 1 & & 12038 & 142048 & $1.00 E-009$ \\
2 & 0.53 & & 12038 & 142048 & $1.00 E-009$ \\
3 & 0.53 & 11.8 & 17114 & 201945 & $1.00 E-009$ \\
4 & 1.52 & & 17114 & 201945 & $1.00 E-009$ \\
5 & 1.52 & & 19870 & 234466 & $1.00 E-009$ \\
6 & 2.41 & & 19870 & 234466 & $1.00 E-009$ \\
\hline
\end{tabular}

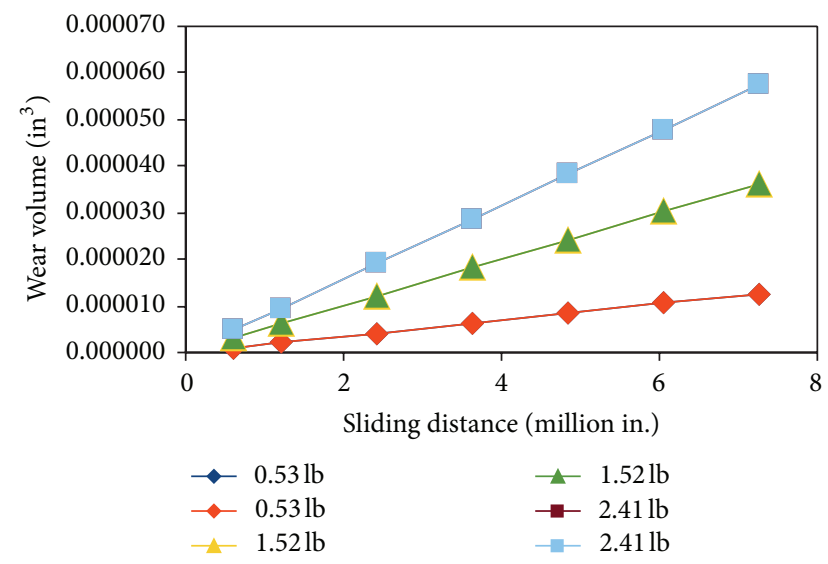

FIGURE 10: Graphs of wear against sliding distance for 1060 steel ball on Torlon 4301 polymer at various loads, velocity $11.8 \mathrm{ft} / \mathrm{min}$.

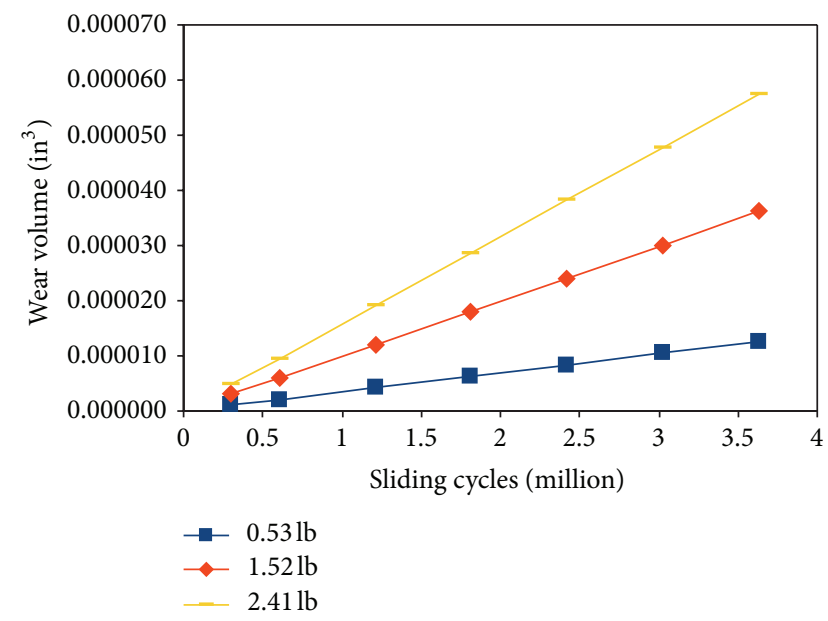

FigURE 11: Graphs of wear against number of sliding cycles for 1060 steel ball on Torlon 4301 polymer at various loads, velocity $11.8 \mathrm{ft} / \mathrm{min}$.

sliding surfaces reverses in a periodic fashion such that the sliding occurs back and forth in a straight line.

This test involves two specimens-a flat specimen made up of polymer material, namely, Torlon PAI, and a ball specimen made up of 1060 alloy steel, which slides against the flat specimen. The load is applied vertically downwards

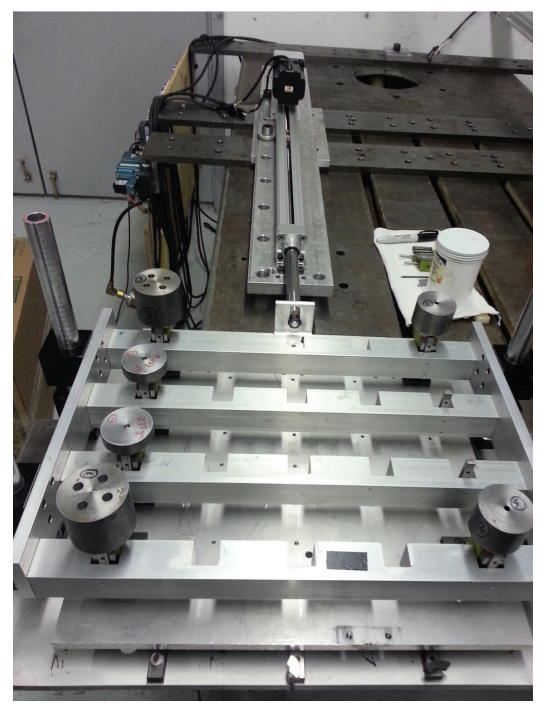

FIGURE 12: Wear test apparatus.

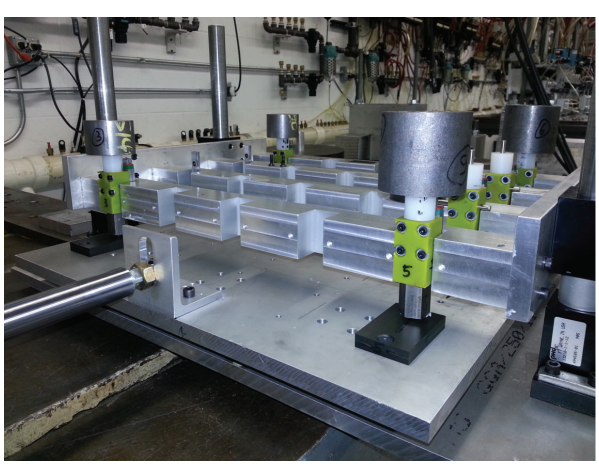

FIGURE 13: Ball and flat mounting arrangement.

through the ball specimen against the horizontally mounted flat specimen, as shown in Figures 12, 13, 14, and 15.

The loads selected in this test are $0.53 \mathrm{lb}, 1.52 \mathrm{lb}$, and $2.41 \mathrm{lb}$. The average sliding velocity is set at $11.8 \mathrm{ft} / \mathrm{min}$. The test apparatus as shown in Figure 12 consists of a fixture which contains a number of ball holders arranged at equal distances. A moving platform contains all the flat specimens securely fastened to it. The platform is provided with linearly reciprocating motion by a linear actuator powered by a servo motor. 


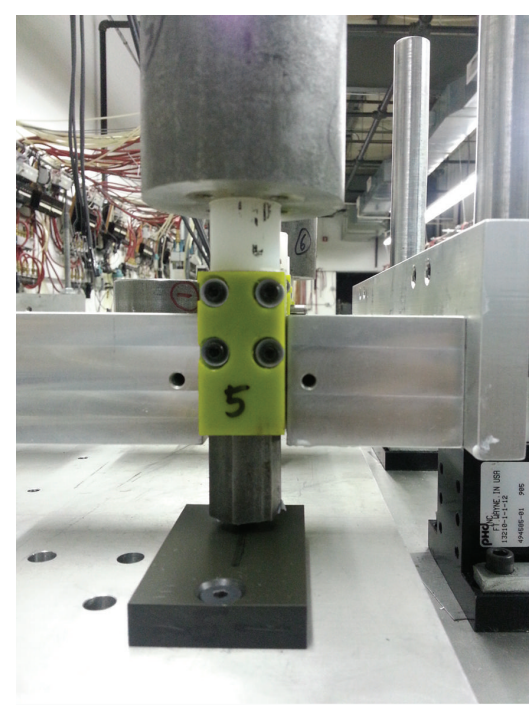

FIGURE 14: Wear on the flat specimen caused by the sliding ball.

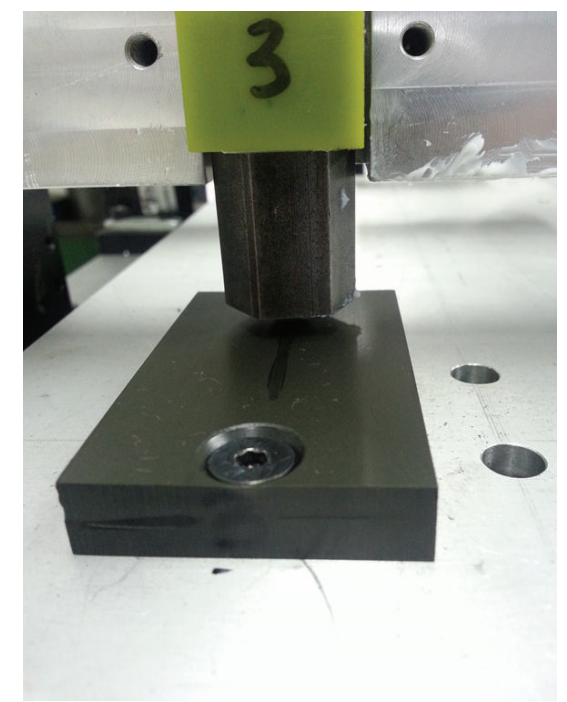

Figure 15: Closer view of the wear band on the flat.

The actuator is programmed to move the platform in a smooth reciprocating motion without any sudden acceleration and deceleration. The amount of travel in one direction is set to be $1 \mathrm{in}$., therefore a total travel of 2 inches per cycle. The rate at which the cycle is set to repeat itself is determined by the allowable duty cycle of the servo motor used in the test. The rate is therefore set at 30 cycles/minute.

Wear measurements are taken at periodic intervalstypically one to two weeks, using a dial indicator with a resolution of $0.0001 \mathrm{in}$. Additionally, wear profile is recorded using a profilometer. The measured values are shown in Table 4 .

Comparison of the wear volumes between the wear model as shown in Table 3 and the measured wear values from the wear test shown in Table 4 exhibits a good correlation. The

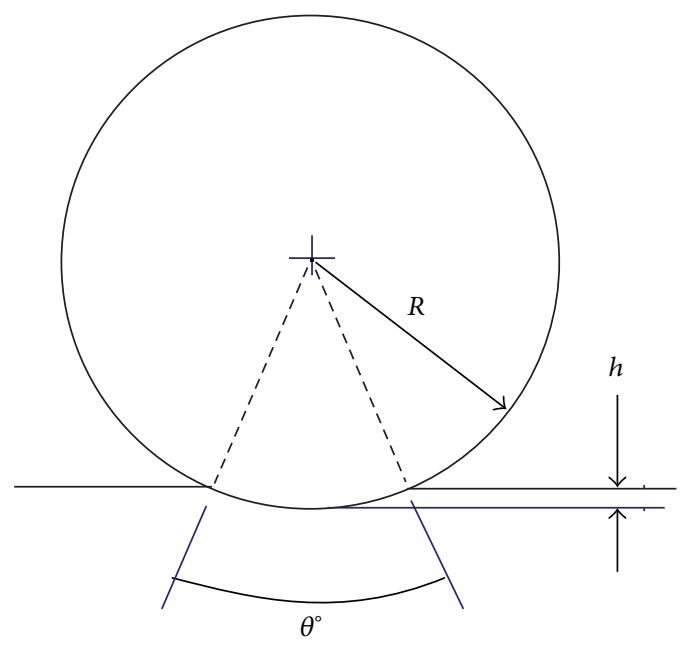

FIgURE 16: Ball and plate contact area.

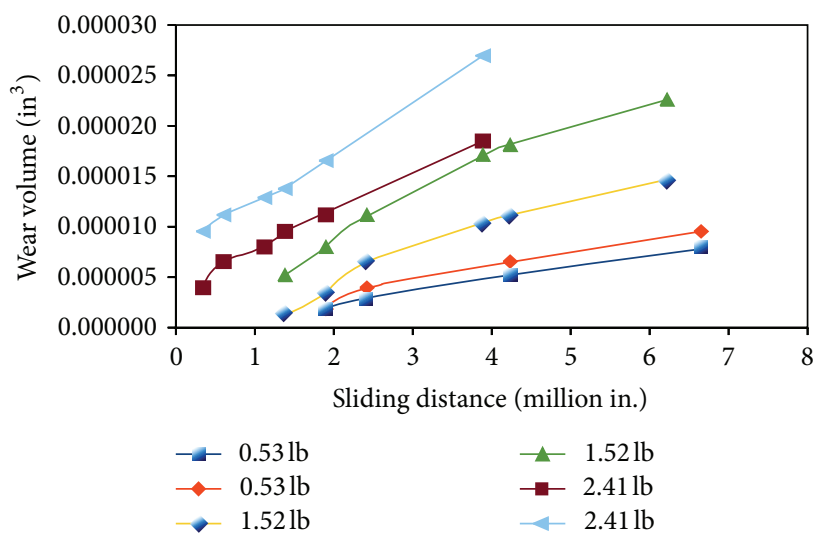

FIGURE 17: Graphs of measured values of wear against sliding distance for 1060 steel ball on Torlon 4301 polymer at various loads, velocity $11.8 \mathrm{ft} / \mathrm{min}$.

values per the wear model are generally greater than the test values by a factor of 1.3 to 1.5 .

4.2. Lead Screw Wear Model. The simulated wear test and the analytical wear model's results are thus used to generate a wear model for the lead screw actuator. In this process the first step is to evaluate the contact stresses that are developed at the lead screw and nut interface, by performing finite element analysis of the screw and nut assembly using NEi Nastran software. In order for the numerical solution in this analysis to converge, a very fine meshed model is required. But as a fine meshed model results in a large number of elements and the corresponding degrees of freedom, a symmetric quarter model is used, as shown in Figure 18. The assembly model used (as shown in Figure 18) as an example consists of a $12 \mathrm{~mm}$ diameter trapezoidal screw and nut assembly with a pitch of $3 \mathrm{~mm}$. An axial load of $40 \mathrm{lb}(177 \mathrm{~N})$ is applied to the screw, whereas the nut is applied constraints to prevent translation in X-direction. Since a symmetric quarter model 
TABLE 3: Wear volume as a function of sliding distance.

\begin{tabular}{|c|c|c|c|c|c|c|c|}
\hline \multirow{2}{*}{ Sliding distance } & \multicolumn{7}{|c|}{ Wear volume $\left(\mathrm{in}^{3}\right)$} \\
\hline & & & & & & & \\
\hline Days & 7 & 14 & 28 & 42 & 56 & 70 & 84 \\
\hline Hours & 168 & 336 & 672 & 1008 & 1344 & 1680 & 2016 \\
\hline Million inches & 0.6048 & 1.2096 & 2.4192 & 3.6288 & 4.8384 & 6.048 & 7.2576 \\
\hline \multicolumn{8}{|l|}{ Sample no. } \\
\hline 1 & 0.000001 & 0.000002 & 0.000004 & 0.000006 & 0.000008 & 0.000011 & 0.000013 \\
\hline 2 & 0.000001 & 0.000002 & 0.000004 & 0.000006 & 0.000008 & 0.000011 & 0.000013 \\
\hline 3 & 0.000003 & 0.000006 & 0.000012 & 0.000018 & 0.000024 & 0.000030 & 0.000036 \\
\hline 4 & 0.000003 & 0.000006 & 0.000012 & 0.000018 & 0.000024 & 0.000030 & 0.000036 \\
\hline 5 & 0.000005 & 0.000010 & 0.000019 & 0.000029 & 0.000038 & 0.000048 & 0.000057 \\
\hline 6 & 0.000005 & 0.000010 & 0.000019 & 0.000029 & 0.000038 & 0.000048 & 0.000057 \\
\hline
\end{tabular}

TABLE 4: Measured value of wear from the wear test for 1060 steel ball on Torlon 4301 polymer at various loads.

\begin{tabular}{|c|c|c|c|c|c|c|c|c|}
\hline \multicolumn{9}{|c|}{ Wear volume $\left(\mathrm{in}^{3}\right)$} \\
\hline \multicolumn{9}{|l|}{ Sliding distance } \\
\hline (Million inches) & 1.1232 & 1.3824 & 1.9008 & 2.4192 & 3.888 & 4.2336 & 6.2208 & 6.6528 \\
\hline \multicolumn{9}{|l|}{ Sample no. } \\
\hline 1 & & & 0.000002 & 0.000003 & & 0.000005 & & 0.000008 \\
\hline 2 & & & 0.000002 & 0.000004 & & 0.000007 & & 0.000010 \\
\hline 3 & & 0.000001 & 0.000003 & 0.000007 & 0.000010 & 0.000011 & 0.000015 & \\
\hline 4 & & 0.000005 & 0.000008 & 0.000011 & 0.000017 & 0.000018 & 0.000023 & \\
\hline 5 & 0.000008 & 0.000010 & 0.000011 & & 0.000018 & & & \\
\hline 6 & 0.000013 & 0.000015 & 0.000017 & & 0.000027 & & & \\
\hline
\end{tabular}

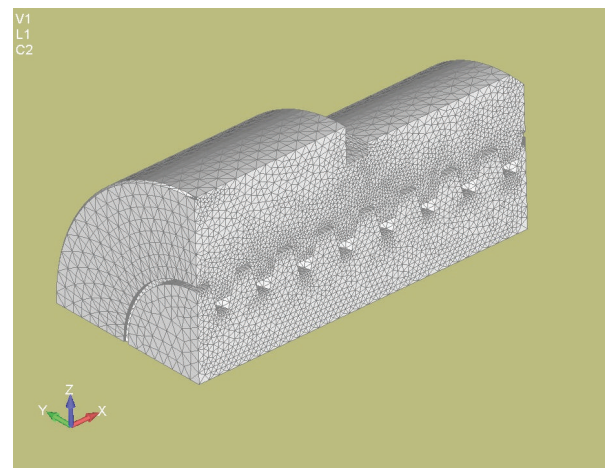

FIGURE 18: Symmetric quarter model of the lead screw and nut assembly.

of the assembly is analyzed, the load applied is one-fourth of the total load, which is $160 \mathrm{lb}(708 \mathrm{~N})$.

The results of the analysis are shown in graphical form in Figures 19 and 20. The distribution of von Mises stresses in the polymer nut and the mating steel screw are shown in Figures 19(a), 19(b), and 19(c). It can be seen in Figure 19(b) that the maximum stress in the nut is concentrated on the first thread, that bears the axial force transmitted by the screw, and also that this stress reduces in the subsequent threads in contact. An area of high stress concentration as seen in Figure 19(b) at the top left-hand corner of the nut should be ignored, since it is caused by the addition of a low-stiffness stabilizing spring element to stabilize the finite element model during analysis. Figures 20(a) and 20(b) show the total translation, caused by elastic deformation, in the assembly and the nut.

The second step in this process of generating a wear model for the lead screw actuator is to combine the wear formulation from Section 3 with the test results from Section 4 and apply a correction factor to the wear constant, $K$, and develop a wear equation of lead nut (8):

$$
W=K_{a} F V t
$$

where $K_{a}=$ adjusted wear contant $\left(\right.$ in $\left.^{3}-\mathrm{min} / \mathrm{ft}-\mathrm{lb}-\mathrm{hr}\right), F=$ normal load (lb), $V=$ sliding velocity $(\mathrm{ft} / \mathrm{min})$, and $t=$ total elapsed time (hr).

\section{Conclusion}

In this paper, the multidisciplinary design problem of lead screw linear actuators is discussed and formulated. The mathematical models of wear have been developed to correspond the load with fatigue life of actuators. The models have been validated by the test data and simulation data from finite element analysis. The presented work has its significance in predicting fatigue lives of low-cost linear actuators and contributing to the optimization of robotic design. The presented methodologies can be extended to deal with multidisciplinary designs of other machine components.

The adhesive sliding wear model based on Archard's wear law has proven to demonstrate very good results with 


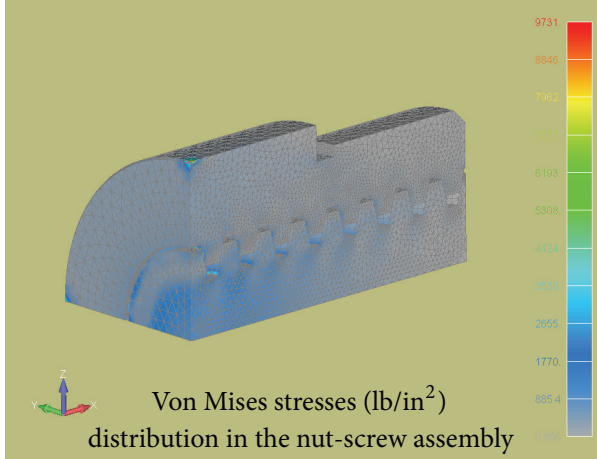

(a)

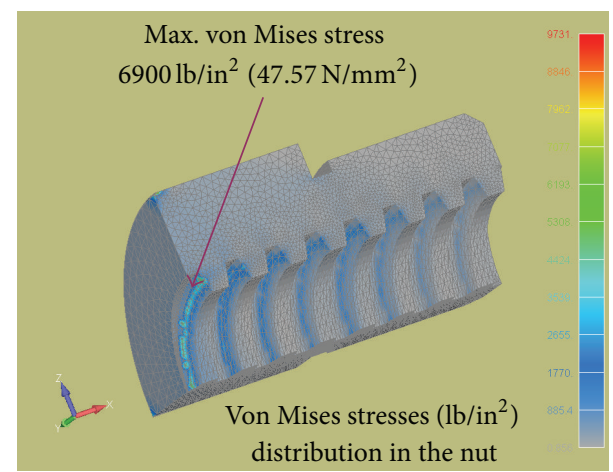

(b)

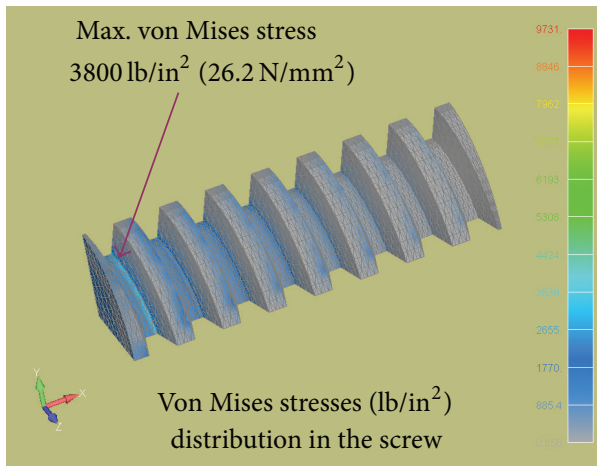

(c)

Figure 19: Von Mises stress distribution in (a) assembly, (b) nut, and (c) screw.

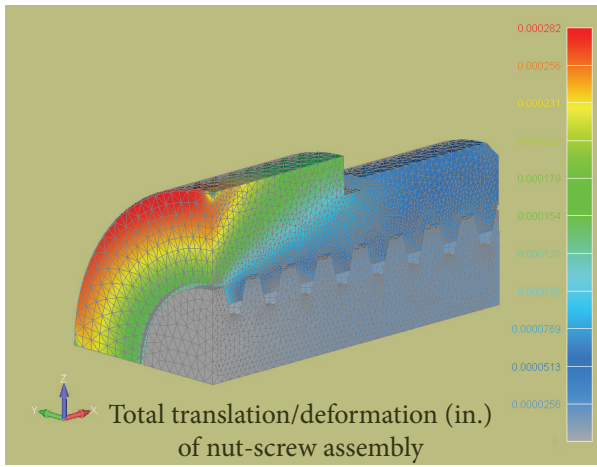

(a)

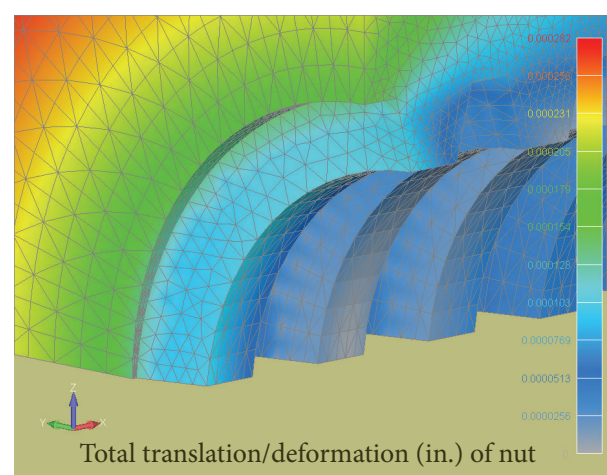

(b)

FIgURE 20: Total translation (deformation) in the (a) assembly and (b) nut.

the material pair of steel and Torlon. The most important factor in this model is the wear factor, $K$, which is a function of the product of pressure and velocity of the sliding contact motion. For the material considered in this paper, Torlon PAI, the values of $K$, depending on the $P V$ value, vary from $10 \times 10^{-10}$ to $50 \times 10^{-10} \mathrm{in}^{3}-\mathrm{min} / \mathrm{ft}-\mathrm{lb}$-hr. The calculated volumetric wear, as shown in Table 3 , is based on a $K$ value of $10 \times 10^{-10}$. At this value, the estimated wear from tests and the calculated wear are very close to each other, as is evident from Figures 10 and 17. However, if the value of $K$ considered is greater than $10 \times 10^{-10}$, then the theoretical and actual wear volume begins to drift apart. Therefore considering the right $K$ value based on $P V$ value is very important, for accurately predicting wear using this model.

Finally, in predicting wear and fatigue life for various loading conditions for lead screw actuators it is very important to consider the correct wear constant value, depending on the $P V$ value of the actuator's application. Further studies could be conducted to eliminate the effect of $P V$ value on the wear constant, and as proposed by Archard and Hirst [19], use a constant related to the probability per unit encounter of production of a wear particle. 


\section{Acknowledgments}

The authors would like to gratefully acknowledge PHD, Inc., Fort Wayne, IN, USA, for supporting this work and providing the necessary resources required for modeling and verification of the wear model. The authors would also like to acknowledge and thank the effort of Mr. Puneeth Meruva, Fort Wayne, IN, USA, for his valuable assistance in conducting the research and help with the compilation and analysis of the data.

\section{References}

[1] Bill Gates, "Robots Will Be The Next World-Changing Technology," 2013, http://finance.yahoo.com/news/bill-gates-robotsnext-world-134500596.html.

[2] Z. M. Bi and W. J. Zhang, "Concurrent optimal design of modular robotic configuration," Journal of Robotic Systems, vol. 18, no. 2, pp. 77-87, 2000.

[3] Z. M. Bi and W. J. Zhang, "Modularity technology in manufacturing: taxonomy and issues," International Journal of Advanced Manufacturing Technology, vol. 18, no. 5, pp. 381-390, 2001.

[4] Z. M. Bi, W. J. Zhang, I. M. Chen, and S. Y. T. Lang, "Automated geneartion of the $\mathrm{D}-\mathrm{H}$ parameters for configuration design of modular manipulators," Robotics and Computer-Integrated Manufacturing, vol. 23, no. 5, pp. 553-562, 2007.

[5] Z. M. Bi, W. A. Gruver, W. J. Zhang, and S. Y. T. Lang, "Automated modeling of modular robotic configurations," Robotics and Autonomous Systems, vol. 54, no. 12, pp. 1015-1025, 2006.

[6] Z. M. Bi and Y. Jin, "Kinematic modeling of Exechon parallel kinematic machine," Robotics and Computer-Integrated Manufacturing, vol. 27, no. 1, pp. 186-193, 2011.

[7] Z. M. Bi and L. Wang, "Energy modeling of machine tool for optimization of machine setup," IEEE Transaction on Automated Manufacturing Systems, vol. 9, no. 3, pp. 607-613, 2012.

[8] Z. M. Bi, "Design of a spherical parallel kinematic machine for ankle rehabilitation," Advanced Robotics, vol. 27, no. 2, pp. 121132, 2013.

[9] Z. M. Bi and B. Kang, "Enhancement of adaptability of parallel kinematic machines with an adjustable platform," ASME Journal of Manufacturing Science and Engineering, vol. 132, no. 6, Article ID 061016, 2010.

[10] SKF, "Roller screws," 2013, http://www.skf.com/files/779280 .pdf.

[11] D. B. Marghitu, Kinematic Chains and Machine Components Design, Elsevier Academic Press Publication, 2005.

[12] V. B. Bhandari, Design of Machine Elements, Tata McGraw-Hill, 2008.

[13] J. T. Burwell, "Wear tests and service performance," in Interpretation of Tests and Correlaion With Service, pp. 88-140, American society for metals, Cleveland, Ohio, USA, 1957.

[14] E. Rabinowicz, Friction and Wear of Materials, Wily Interscience Publication, 1965.

[15] G. Fuman, F. Tobin, and K. H. Strauss, "Abrasives and wear," Lubrication, vol. 43, pp. 13-24, 1957.

[16] P. P. Love, "Diagnosis and analysis of plain bearing failures," Wear, vol. 1, no. 3, pp. 196-210, 1957.

[17] R. J. Ronan, G. R. Furman, and J. T. Bugbee, "Petroleum laboratory investigations," Lubrication, vol. 44, pp. 29-44, 1958.
[18] ASTM International, "Standard test method for linearly reciprocating ball-on-flat sliding wear," ASTM G 133-05, 2010.

[19] J. F. Archard and W. Hirst, "The wear of metals under unlubricated conditions," Proceedings of the Royal Society A, vol. 236, pp. 397-410, 1956. 


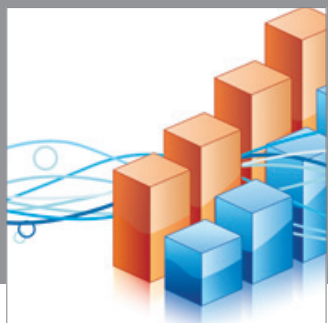

Advances in

Operations Research

mansans

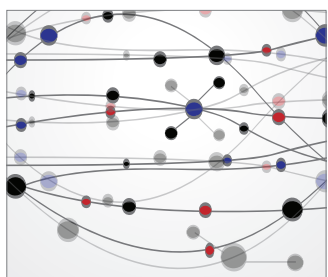

The Scientific World Journal
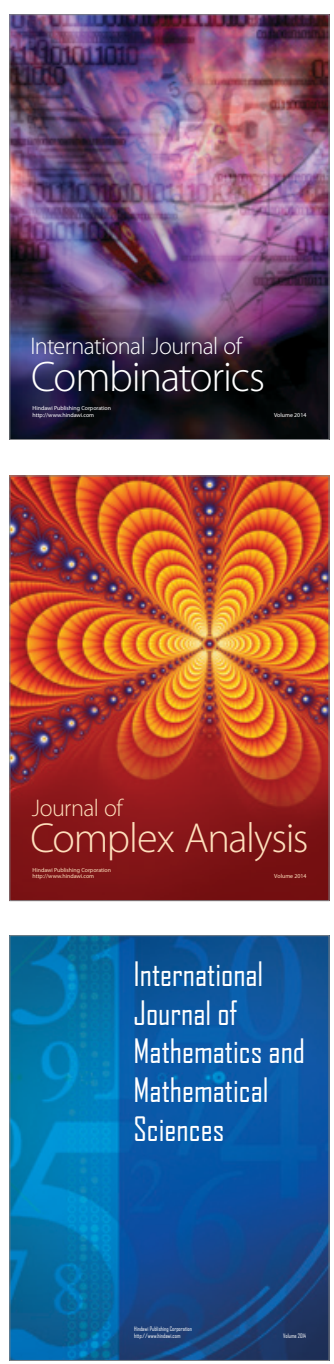
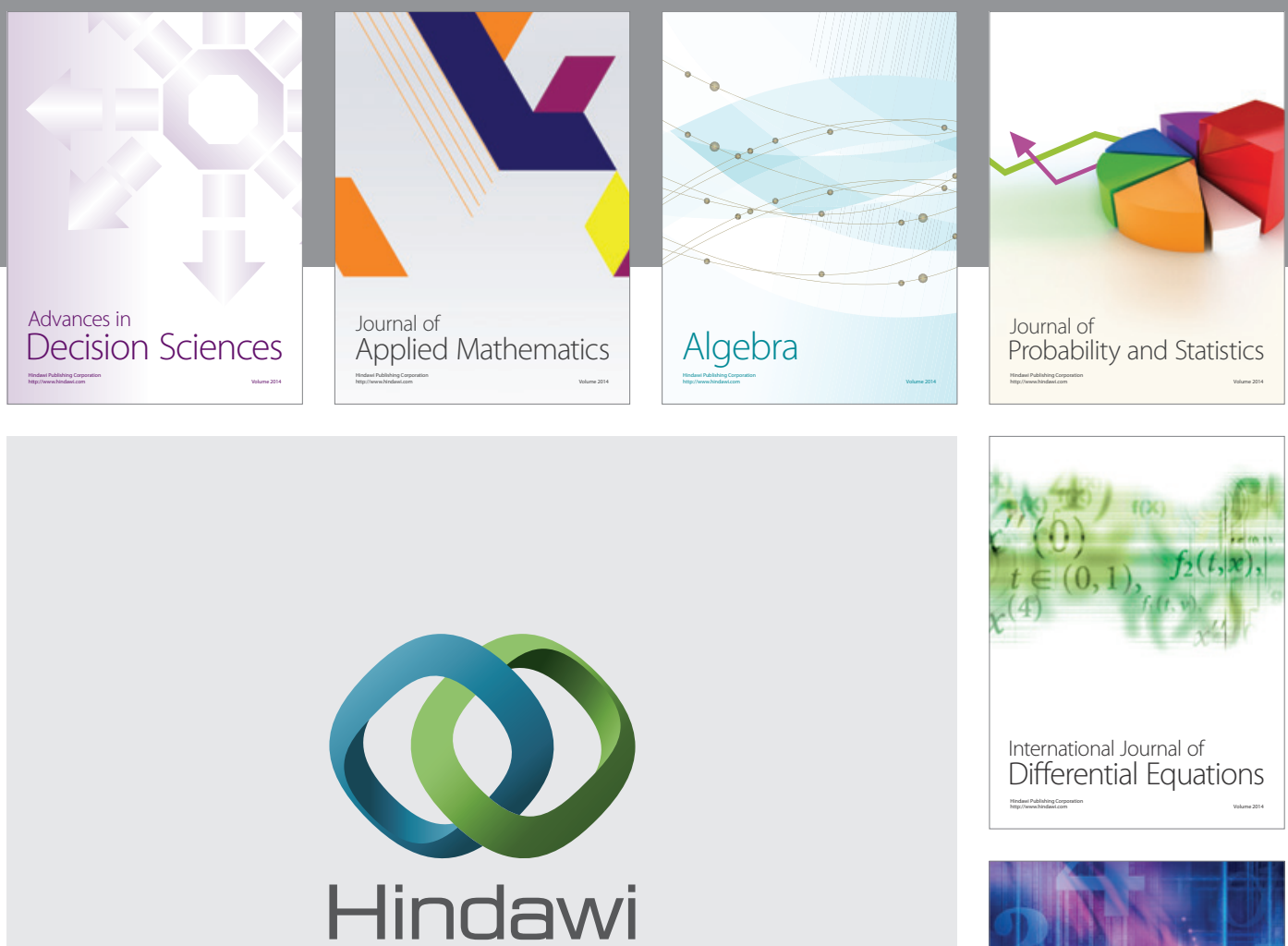

Submit your manuscripts at http://www.hindawi.com
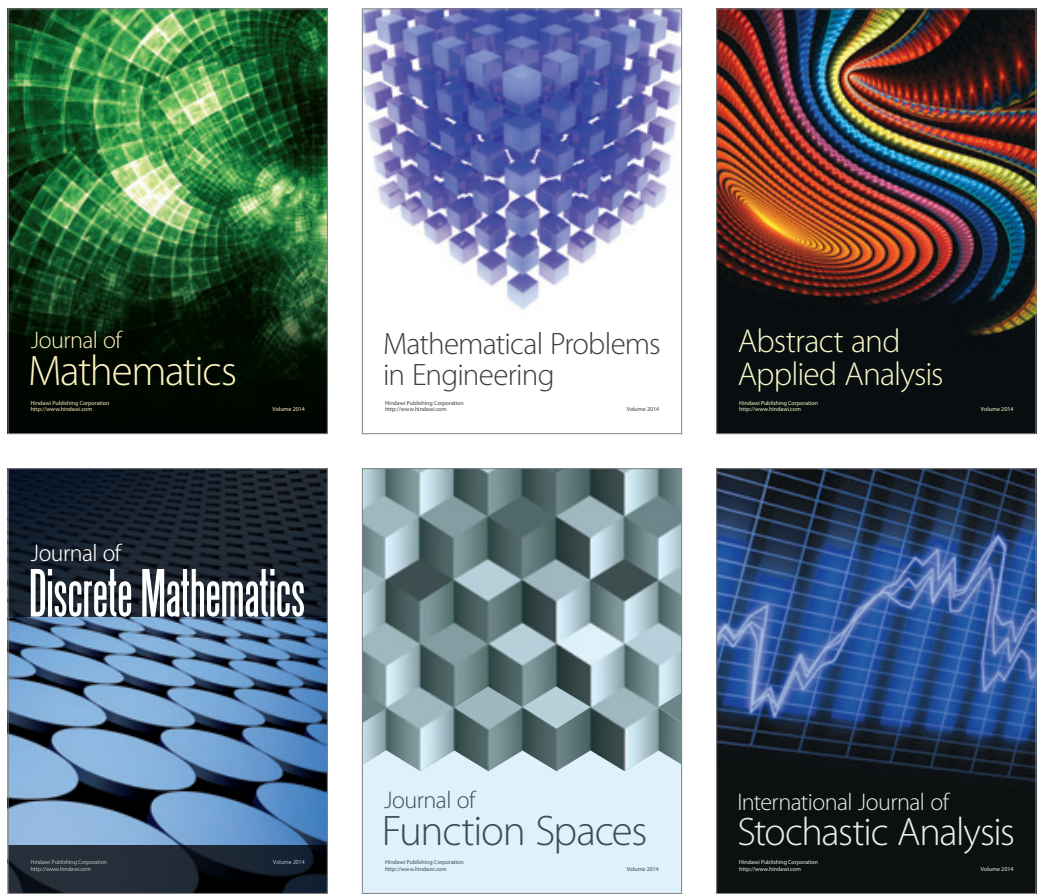

Journal of

Function Spaces

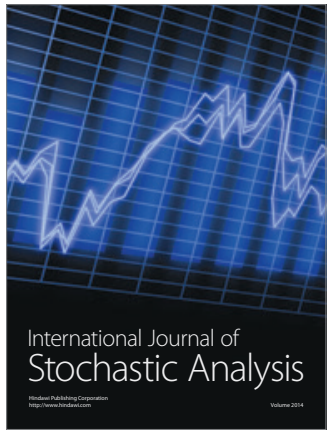

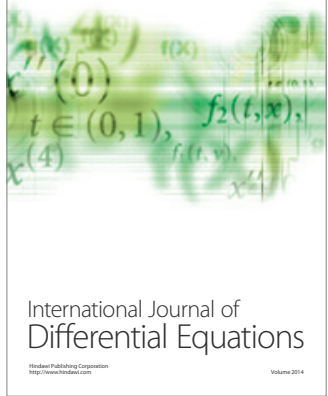
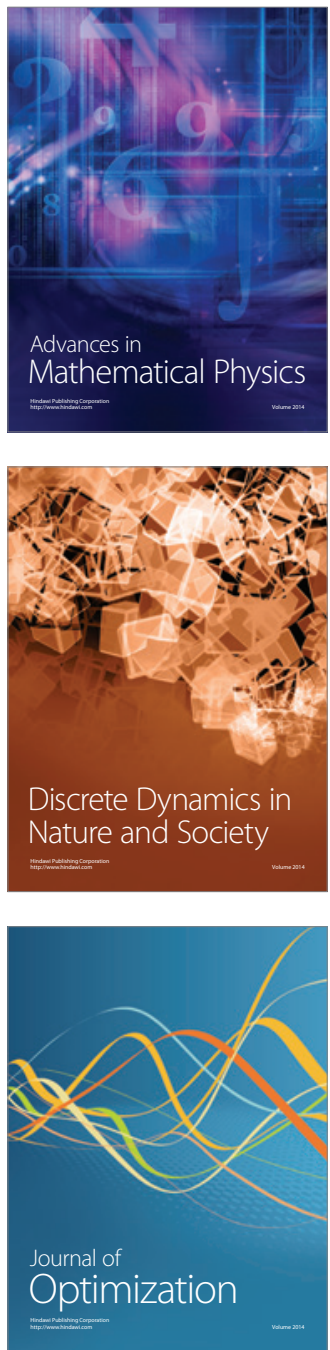